\title{
Trauma ocular por explosão acidental de disco compacto
}

\author{
Ocular trauma due to accidental compact disc outburst
}

Marco Antonio Guarino Tanure', Fábio Medina Rodrigues Rocha ${ }^{2}$

\begin{abstract}
Resumo
Apesar de rara, a ocorrência de lesão ocular devido à explosão acidental de disco compacto pode ser responsável por graves lesões no globo ocular. No presente artigo é relatado caso de perfuração corneana com trauma cristaliniano causado pela quebra intencional de disco compacto. Trata-se de paciente com 44 anos, sexo feminino, médica, avaliada em caráter de urgência com queixas de BAV, fotofobia, lacrimejamento e sensação de corpo estranho no OD, iniciados após presenciar quebra intencional de disco compacto. Apresentava perfuração corneana central, com sinal de Seidel positivo e lesão de cápsula anterior do cristalino com opacificação cortical anterior subjacente. A AV corrigida no OD era de 0,1. Tratada com lente de contato hidrofílica terapêutica e instilações tópicas regulares de solução antibiótica e hipotensora ocular, evoluiu com cicatrização da lesão corneana e estabilização da opacidade do cristalino. Decorridos 24 meses do trauma, sua refração encontrava-se semelhante aos valores prévios ao acidente e a acuidade visual era de $1,0^{(-1)}$.

Descritores: Ferimentos e lesões; Córnea/leões; Perfuração da córnea; Lentes de contato hidrofílicas; CD-ROM; Relatos de casos

ABSTRACT

Despite being rare, ocular injury due to a compact disc burst can be responsible for severe ocular damage. We present in this article a case of corneal perforation in addition to lens trauma caused by intentional compact disc break. A 44 year old female physician was examined complaining of visual acuity decrease, light sensitivity, tearing and foreign body sensation on OD after watching a compact disc being broken intentionally. In the first examination, she had a corneal perforation with aqueous humor leakage, anterior lens capsule lesion and anterior cortical opacity. The visual acuity was 0.1. She was treated with a therapeutic soft contact lens and the regular use of topical antibiotic and hypotension solutions, evolving with the healing of the corneal injury and lens opacity stabilization. Twenty four months later, the $O D$ refraction was similar to that measured before the trauma and the visual acuity was $1.0^{(-1)}$.
\end{abstract}

Keywords: Wounds and injuries; Cornea/injuries; Corneal perforation; Contact lenses, hydrophilic; CD-ROM; Case reports

\footnotetext{
1 Pós-doutorado em oftalmologia - Thomas Jefferson University (Philadelphia, USA); Responsável pelo Serviço de Catarata do Hospital São Geraldo - Hospital das Clínicas da Universidade Federal de Minas Gerais (UFMG) - Belo Horizonte (MG), Brasil;

${ }^{2}$ Estagiário do Serviço de Córnea, Catarata e DEO do Hospital São Geraldo - Hospital das Clínicas da Universidade Federal de Minas Gerais (UFMG) - Belo Horizonte (MG), Brasil.

Instituição: Serviço de Córnea, Catarata e DEO do Hospital São Geraldo - Hospital das Clínicas da Universidade Federal de Minas Gerais (UFMG) - Belo Horizonte (MG), Brasil
} 


\section{INTRODUÇÃO}

$\mathbf{R}$ elatos de trauma ocular causados por disco compacto (CD) são raros na literatura. Em 1998, Ing $^{(1)}$ descreveu um caso de extensa laceração córneo-escleral, com hemorragia vítrea e descolamento de retina em jovem atingida por CD lançado ao público como brinde, durante apresentação de conjunto musical. O único relato encontrado na literatura de trauma ocular por fragmentos de CD após sua quebra acidental foi feito por Bialasiewics \& Richard $^{(2)}$ em 1999, no qual descrevem caso de criança de 9 anos atingida em um dos olhos por fragmento de $\mathrm{CD}$, que explodiu durante tentativa de dobrá-lo ao meio. Houve perfuração da córnea e do cristalino, com perda vítrea e AV final de 0,1 . No presente artigo, descreve-se caso de perfuração corneana e penetração cristaliniana por fragmento de $\mathrm{CD}$ após a sua quebra intencional, resultando em pequeno leucoma, opacificação cristaliniana localizada e não progressiva e apenas discreta redução da AV após 18 meses de seguimento.

\section{Relato de Caso}

Paciente com 44 anos, do sexo feminino, médica, avaliada em caráter de urgência com queixa de baixa da AV, sensação de corpo estranho ocular, lacrimejamento e fotofobia no OD, iniciados após presenciar, juntamente com suas filhas e esposo, a quebra intencional de um $\mathrm{CD}$ em sua residência, com o objetivo de identificar as diferentes camadas que constituíam o mesmo. Ao exame, apresentava AV de 0,1, hiperemia pericerática, perfuração corneana central-superior com sinal de Seidel positivo (Figura 1A e 1B), mas a câmara anterior encontrava-se apenas discretamente mais rasa que a do olho contralateral. Também na região central superior do cristalino verificava-se pequena laceração da cápsula anterior com opacificação cortical anterior subjacente de formato circular e com cerca de $1,0 \mathrm{~mm}$ de diâmetro. No centro da opacificação, em posição sub-capsular, era possível identificar área transparente, sugestiva de se tratar de pequeno fragmento plástico do $\mathrm{CD}$ ali alojado (Figura 2A). No vítreo anterior não se observava a presença de hemácias ou células inflamatórias e o exame de fundo do olho encontrava-se normal. Devido ao aspecto biselado da ferida corneana, sem perda de tecido e à boa profundidade da câmara anterior, optou-se por tratamento clínico com a colocação de lente de contato hidrofílica $(\mathrm{LCH})$, colírio hipotensor (cloridrato de dorzolamida a $2 \%$ e maleato de timolol a $0,5 \%$ ) de $12 / 12 \mathrm{~h}$ e solução tópica de moxifloxacino a $0,5 \%$ de $2 / 2 \mathrm{~h}$. Após 4 dias, como a perfuração corneana já se encontrava ocluída e não havia sinais de ceratite ou endoftalmite infecciosas, a LCH foi retirada, o colírio hipotensor suspenso e as instilações da solução moxifloxacino reduzidas para $4 / 4 \mathrm{~h}$ por mais 3 dias. Decorridos 4 meses do trauma, a paciente queixava de discreta BAV no OD, que a incomodava apenas ocasionalmente (assistir aulas em congressos, por exemplo) e a AV era de 0,9 com correção de $-0,75$ $0,25 \times 85^{\circ}$ (antes do trauma, usava correção de $-0,75$ esférico neste olho, com visão de 1,0). A lesão corneana encontrava-se ocluída, sem edema ou infiltração e a opacificação cristaliniana mantinha-se inalterada. Na última avaliação realizada, 24 meses após o trauma, a queixa de BAV era ainda mais ocasional e a AV era de $1,0^{(-1)} \operatorname{com}-0,75-0,25 \times 120^{\circ}$. A área de opacificação cristaliniana mantinha-se inalterada, assim como a localização do possível fragmento de CD intracristaliniano (Figura 2B). Em todas as avaliações realizadas após a oclusão da perfuração corneana, as medidas da pressão intraocular mantiveram-se dentro dos limites da normalidade.

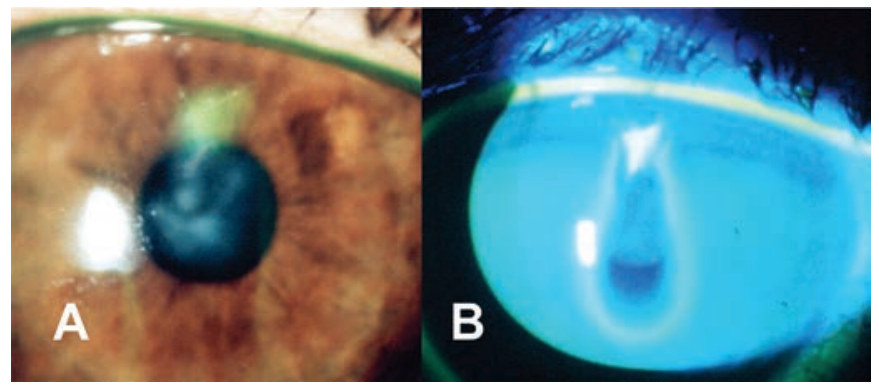

Figura 1:-A) Perfuração de córnea central-superior (seta) e opacidade cristaliniana em exame realizado poucas horas após o acidente; B) Sinal de Seidel presente no exame inicial

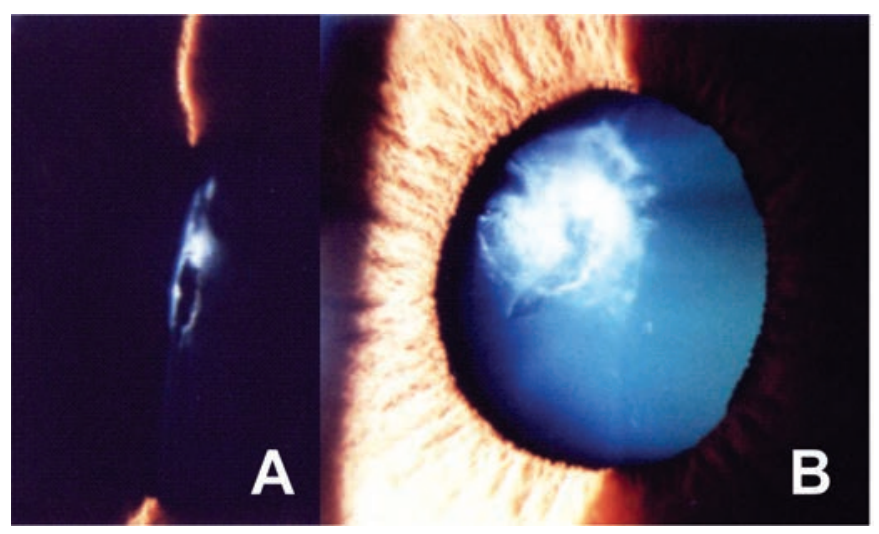

Figura 2: A) Área transparente no centro da opacidade (seta) sugestiva de fragmento plástico alojado sob a cápsula anterior; B) Opacidade cristaliniana cortical anterior após 24 meses do acidente

\section{Dıscussão}

Os discos compactos atualmente utilizados para armazenamento de dados e áudio são constituídos por camadas metálicas envolvidas por plásticos rígidos, entre eles o policarbonato. Quando submetidos a tensões excessivas em sua estrutura, como a tentativa de dobrá-los ao meio, os CDs podem se quebrar como numa explosão, remetendo em várias direções e em alta velocidade fragmentos plásticos cortantes. Caso esses fragmentos atinjam a superfície ocular podem penetrar o globo ocular e causar graves lesões como ceratites, catarata, lesões vítreorretinianas e endoftalmites. Bialasiewics \& Richard ${ }^{(2)}$ relataram caso de perfuração ocular com perda vítrea e AV final de 0,1 em criança de 9 anos após a explosão de um CD durante a tentava dobrá-lo ao meio.

Casos de catarata traumática com presença de corpo estranho intracristaliniano podem ser conduzidos apenas com a observação, com a remoção do corpo estranho e preservação do cristalino ou de forma mais agressiva, com a realização de facectomia com ou sem implante de lente intraocular ${ }^{(3,4)}$. Relatos de casos de cataratas traumáticas que com o tempo permaneceram localizadas sem maiores interferências na AV, ou mesmo regrediram, são descritos na literatura ${ }^{(5-7)}$. Quando ocorre a ruptura capsular, imediatamente o cortex subjacente se hidrata e perde sua transparência normal. Nos casos em que a lesão capsular é pequena, uma rápida proliferação do epitélio capsular permitiria a restauração do balanço hidroeletrolítico do cortex cristaliniano, impedindo assim a progressão da $\operatorname{catarata}^{(8)}$.

No presente artigo é descrito caso em que, apesar da ocorrência de perfuração corneana e penetração cristaliniana por provável fragmento plástico de $\mathrm{CD}$, não houve comprometimento 
significativo da AV após 24 meses de evolução, com a opacidade cristaliniana mantendo-se estável neste período. Como a perfuração corneana era pequena e com formato biselado, causando apenas pequena redução da profundidade da câmara anterior, optou-se pelo tratamento conservador com o uso de $\mathrm{LCH}$ e colírios antibiótico e hipotensor.

É importante ressaltar que, diferente do que se observa em outros dispositivos de uso comum, como baterias, aerossóis e aparelhos eletrônicos, raras são as empresas fabricantes de CDs que incluem na sua embalagem informações sobre os riscos relacionados à quebra do produto. Quando estão presentes, as recomendações existentes limitam-se a orientar os usuários quanto aos cuidados para a conservação adequada do CD. Seria, portanto, recomendado que os fabricantes de CDs incluíssem na embalagem do produto informações que alertassem aos consumidores sobre os potenciais riscos de lesões oculares no caso de quebra acidental ou intencional do mesmo.

\section{ReferênCiAs}

1. Ing E. Blinding eye injury during a rock concert. Ophthalmic Surg Lasers. 1998;29(6): 518.

2. Bialasiewics AA, Richard G. Severe penetrating injury due to a burst compact disc in a child. Br J Ophthalmol. 1999;83(5):628.

3. Pieramici DJ, Capone A Jr, Rubsamen PE, Roseman RL. Lens preservation after intraocular foreign body injuries. Ophthalmology. 1996;103(10):1563-7.
4. Moisseiev J, Segev F, Harizman N, Arazi T, Rotenstreich Y, Assia EI. Primary cataract extraction and intraocular lens implantation in penetrating ocular trauma. Ophthalmology. 2001;108(6):1099-103.

5. Cazabon S, Dabbs TR. Intralenticular metallic foreign body. J Cataract Refract Surg. 2002;28(12):2233-4.

6. Dhawahir-Scala FE, Kamal A. Intralenticular foreign body: a DDay reminder. Clin Experiment Ophthalmol. 2005;33(6):659-60.

7. Rofagha S, Day S, Winn BJ, Ou JI, Bhisitkul RB, Chiu CS. Spontaneous resolution of a traumatic cataract caused by an intralenticular foreign body. J Cataract Refract Surg. 2008;34 (6):1033-5.

8. Fagerholm PP, Philipson BT. Human traumatic cataract. A quantitative microradiographic and electron microscopic study. Acta Ophthalmol (Copenh). 1979;57(1):20-32.
Autor correspondente:

Marco Antonio G. Tanure

Rua Padre Rolim, n 515 / 1005

Funcionários

CEP 30130-090 - Belo Horizonte (MG), Brasil

Fone: (31) 3241-4429

E-mail: magt99@yahoo.com 